\title{
Article
}

\section{Catalysing change? A critical exploration of the impacts of a community food initiative on people, place and prosperity}

Farrier, Alan, Dooris, Mark T and Morley, Adrian

Available at http://clok.uclan.ac.uk/29934/

Farrier, Alan ORCID: 0000-0003-4989-2209, Dooris, Mark T ORCID: 0000-00025986-1660 and Morley, Adrian (2019) Catalysing change? A critical

exploration of the impacts of a community food initiative on people, place and prosperity. Landscape and Urban Planning, 192 . p. 103663. ISSN 0169-2046

It is advisable to refer to the publisher's version if you intend to cite from the work.

http://dx.doi.org/10.1016/j.landurbplan.2019.103663

For more information about UCLan's research in this area go to http://www.uclan.ac.uk/researchgroups/ and search for <name of research Group>.

For information about Research generally at UCLan please go to http://www.uclan.ac.uk/research/

All outputs in CLoK are protected by Intellectual Property Rights law, including Copyright law. Copyright, IPR and Moral Rights for the works on this site are retained by the individual authors and/or other copyright owners. Terms and conditions for use of this material are defined in the policies page.

\section{CLoK}

Central Lancashire online Knowledge www.clok.uclan.ac.uk

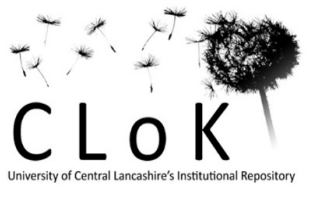


Title

Catalysing change? A critical exploration of the impacts of a community food initiative on people, place and prosperity.

\title{
Authors names and affiliations
}

Alan Farrier

University of Central Lancashire, Preston, Lancashire, UK PR12HE (corresponding author: afarrier@uclan.ac.uk)

\section{Mark Dooris}

University of Central Lancashire, Preston, Lancashire, UK PR12HE (mtdooris@uclan.ac.uk)

Adrian Morley

Manchester Metropolitan University, Manchester, UK M156BG

(a.morley@mmu.ac.uk)

\section{Research Highlights}

- Food can connect people and landscapes, engaging them with wellbeing, ecology and sustainability concerns, and stimulating bottom-up activism linked to wider policy and planning.

- Incredible Edible Todmorden has enhanced the wellbeing of people, place and planet.

- The Incredible Edible three 'spinning plates' model has created a distinctive place-based brand that has gained traction worldwide.

- Whilst not necessarily engaging the whole community, propaganda gardening changes people's perception of/relationship to landscapes and the public realm.

- Innovation and inspirational change can be borne out of creative tensions.

\begin{abstract}
Using food to create edible landscapes, support inclusive community development and build sustainability and local resilience, Incredible Edible Todmorden [IET] is a place-based movement implementing its three 'spinning plates' model to develop and harness local community, business and learning assets. This paper reports on a mixed-methods study that used a Theory of Change workshop, interviews, focus groups and surveys to evaluate IET's social, economic and environmental impacts and assess its wider potential as a community-led framework for improving wellbeing. Whilst highlighting a vein of dissent, cynicism and resistance to change, the findings overwhelmingly demonstrated that IET has enhanced the wellbeing of Todmorden as a 'place' and promoted the wellbeing of its people, in part through changing their relationships with their locality. It has also stimulated awareness of and engagement with local and global sustainability concerns, fostering grassroots
\end{abstract}


activism and engagement with policy and planning governance systems. Alongside this, it has developed a 'model' that has catalysed the global Incredible Edible movement, indicating its potential to be successfully implemented in diverse contexts. This suggests that changing landscapes by opening up public realm and other assets for food growing and wider community expression can be an important and holistic place-making tool.

\section{Introduction}

This paper reports on a research study of Incredible Edible Todmorden (IET), which critically evaluated its social, economic and environmental impacts on the local community and considered its potential as a framework for place-based wellbeing.

The complexity of conceptualising place has increasingly been acknowledged. Broadly speaking, place has been categorised in two ways (MacGillivray and Franklin, 2015): objectively as a space in which one can explore universal aspects of the world; or subjectively from an interpretivist perspective - highlighting temporal and spatial dimensions. Our understanding of place aligns with this latter perspective - understanding places as spaces filled up with meanings, narratives and interpretations which are "flexible in the hands of different people or cultures, malleable over time, and inevitably contested" (Gieryn, 2000:465).

Although the concept of place-making has been present for several decades in urban planning and design (Fincher et al., 2016), it remains contested. A useful definition suggests that it is concerned:

"to improve the quality of a public place and the lives of its community in tandem... to build or improve public space, spark public discourse, create beauty and delight, engender civic pride, connect neighborhoods, support community health and safety, grow social justice, catalyze economic development, promote environmental sustainability, and...nurture an authentic 'sense of place'." (Silberberg et al., 2013:2)

Urban food growing can be understood as an important contributor to sustainable place-making, which involves complex interactions between people and place and between community and government-led strategies (Franklin and Marsden, 2015:954). As Dobson (2014) argues, it can also be influential in trailblazing informal approaches to place-keeping - defined as "responsive long-term management which ensures that the social, environmental and economic quality and benefits a place brings can be enjoyed by present and future generations" (Dempsey, Smith and Burton, 2014).

It has a long and varied history, embracing allotments, farms, community gardens and counter-cultural activities such as guerrilla gardening (Hardman et al., 2018). As Coles and Costa (2018) reflect, a diversity of motivations - ranging from local food production to aesthetic enhancement to expressions of identity linked to political activism and redefinition of the public realm - can inform both the planned and unplanned evolution of landscapes. Whilst it is generally acknowledged that, within the Global North, urban food growing has had only limited impact on food provision and security (Wiltshire and Geoghegan, 2012), it is widely understood to have a range of other benefits: building resilience in communities (Dobson, 2017); 
empowering local people, including providing space for marginalised groups (White and Bunn, 2017); improving psychological health and wellbeing (Gascon et al., 2015) increasing levels of exercise (Çelik, 2017); addressing ecology and sustainability challenges (Purcell and Tyman, 2015); tackling inequalities (Barron, 2017); promoting food justice (Hardman, Adams, Barker and Beesley, 2019); combating social isolation (Marovelli, 2019) and fostering community connectedness and cooperation (Veen et al., 2016). However, its practices remain contested: on the one hand, it is lauded for challenging neoliberalism through resisting the erosion of 'the commons', championing bottom-up landscaping and ecological activism and offering alternatives to exploitative and unsustainable food and planning systems; on the other hand, it has been labelled a neoliberal practice that fuels gentrification and widens societal disparities (Certomà and Tornaghi, 2015).

Best known for community food growing in public spaces, IET is a holistic sustainable food initiative that aims to transform the way people engage with food. IET was founded in 2007 in Todmorden, a West Yorkshire market town of 15,000 people (ONS, 2011a) in the North of England (see Table 1 for demographic data).

\begin{tabular}{|l|c|}
\hline & $\begin{array}{c}2011 \text { Census } \\
\text { for } \\
\text { Todmorden } \\
\text { Parish }\end{array}$ \\
\hline Total Population (number of people) & 15,481 \\
\hline Age (percent) & \\
\hline $18-24$ & 9 \\
\hline $25-64$ & 33 \\
\hline $45-64$ & 37 \\
\hline $65+$ & 21 \\
\hline Gender (percent) & \\
\hline Female & 52 \\
\hline Male & 48 \\
\hline & \\
\hline Ethnicity (percent) & 91.8 \\
\hline White & 5.2 \\
\hline Black and Minority Ethnic & 3 \\
\hline Other & \\
\hline
\end{tabular}

Table 1: Demographic Data for Todmorden (ONS, 2011a; 2015)

Todmorden has a population of less than 16,000 (ONS, 2011a) and is a predominantly White British town (91.8\%), with non-White population of $8.2 \%$, much lower than the national average (20.2) (ONS, 2011b). The age structure is broadly similar to the UK as a whole (ibid.) and $17.5 \%$ of the population are described as 'income deprived' (Index of Multiple Deprivation, 2015). This increases to $22.9 \%$ for families of children aged $0-15$ and $18.7 \%$ for those aged 60 or over, all higher than the national averages. It is a former mill-town and as such saw a significant decline in local employment opportunities when the mills began to close in the 1960s and 1970s. Health and care indicators are also significantly higher than the English rates on the whole (ibid.). 
IET emerged through the efforts of Todmorden community members concerned about the town's decline and a growing disconnect between people and their environment (Paull, 2011; Dobson, 2014). Using the mantra 'if you eat, you're in', IET views food as a universal language for engaging people and addressing local environmental, social and economic challenges (Clarke, 2010). It is widely perceived to have impacted on place-related wellbeing determinants, playing a key role in transforming the town through the development of green productive landscapes, improving living environments, access to food and facilitating an economic uplift (Hardman, Adams, Barker and Beesley, 2019; Warhurst and Dobson, 2014). Moreover, this has largely been achieved by self-starting volunteers (Thompson, 2012; Dobson, 2014).

Its success has catalysed a global movement, which since 2012 has been supported by the Incredible Edible (IE) Network (IEN, 2019). There are now over 100 UK-based IE groups (Incredible Edible, undated) and more than 500 internationally (The Guardian, 2018). To join, groups must signal commitment to the model's guiding metaphor of three 'spinning plates', represented by Lee-Woollf (2011) in Figure 1.

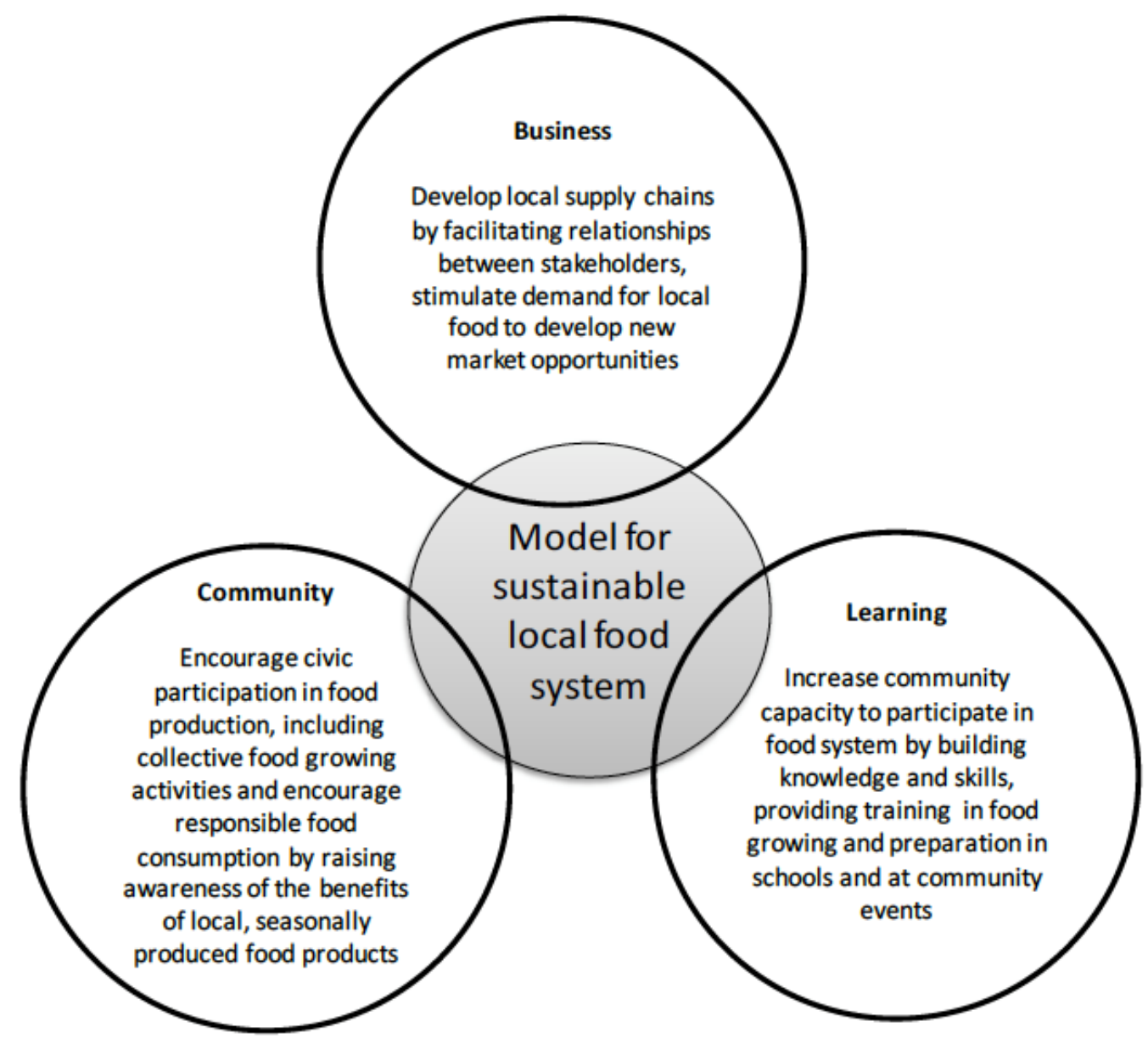

Figure 1: The IE model for a sustainable food system in Todmorden (Lee-Woollf, 2009: 29) 
- Community: Food growing in public spaces for public consumption, shifting from 'guerrilla planting' (gardening without permission on land often abandoned or not cared for) (Certomà, 2011) to 'propaganda gardening' (usually with permission and designed to provoke public and private discourse) (Paull, 2013).

- Business: Supporting local food-related enterprises and supply chains, including use of the IE 'brand' by local businesses.

- Learning: Providing education, training and skills development across the lifecourse and within community settings.

Inevitably, the plates interconnect when translated into activities. For example, the Incredible Todmorden Way, a walking route encompassing the main growing areas in the town, not only facilitates exercise and access to the food but also promotes informal learning using educational display-boards and enables people to discover the town's market, cafés and shops (Dobson, 2014). The IET 'offshoot' initiatives, Incredible Farm and Incredible AquaGarden, are social enterprises concerned with fostering community spirit and enhanced learning (Warhurst and Dobson, 2014). This ability to operate holistically across all three plates is understood to maximise IET's potential positive impact (ibid.).

This paper reports on a study conducted during 2016-17 by researchers from the Sustainable Food North West Research Collaboration. Although there is a wealth of literature on urban food growing and community food systems, as detailed above, IE - and IET specifically - has established a high profile within practice that is not reflected in academic literature. Whilst it has been the subject of previous research projects (e.g. Thompson, 2012), newspaper articles (e.g. The Guardian, 2018), masters and doctoral theses (e.g. Lee-Woolf, 2009), reports (e.g. Trivelli, 2013), peer-reviewed publications (e.g. Thompson, 2012) and book chapters (e.g. Hardman, Adams, Barker and Beesley, 2019), these have focused on specific elements. Taking a broader perspective, this study sought to add value to the field by: critically evaluating the social, economic and environmental impacts of IET on the local community in relation to the 'spinning plates' model; and assessing its wider potential as a community-led framework for wellbeing.

\section{Methods}

To examine IET holistically, a transdisciplinary mixed-methods approach was used. Alongside a contextual literature review, qualitative and quantitative data collection methods included: a theory of change stakeholder workshop; semi-structured one-toone interviews and focus groups; a community survey; a volunteer survey; and a social return on investment analysis (Morley, Farrier and Dooris, 2017). This paper focuses on findings from the first three of these, which were closely interrelated. It therefore has an interpretive focus (Denzin and Lincoln, 2008) and is concerned with the perceived impacts of IET, and specifically the IET model, on the local community and key people involved in the development of IET.

\subsection{Theory of Change stakeholder workshop}

A Theory of Change (ToC) is a conceptual framework for understanding how an organisation or project brings about the change required to achieve its intended outcomes. A ToC is usually presented as a flow chart showing the key steps and interrelationships between activities, outcomes and goals - and the process of generation is often participatory, with input from practitioners and other stakeholders. The approach is based on 'backcasting' principles, where stakeholders first define 
future aspirations and then identify the steps that lead to these long-term goals (Connell and Kubisch, 1998; Taplin and Clark, 2012).

IET developed without the use of an articulated ToC. However, it was agreed with the research project oversight group that it would be valuable to undertake the participatory development of a ToC with local community members with experience of and interest in IET. It was anticipated that this would provide a valuable framework for those involved in the IE movement, as well as helping the research team gain insight into its perceived and expected impacts. In total, thirty community members were recruited, by word-of mouth and e-mail from the IET Community Group, to take part in a workshop to co-produce a ToC (see Figure 2). The workshop was held after a regular volunteering session to promote attendance by individuals with a strong understanding of IET in practice. Participants self-selected to join one of three groups focused on IET's three 'spinning plates'- community, business and learning, with approximately ten community members working on each. They agreed on future long-term (10+ years) ambitions, before working backwards - identifying mediumterm (4-10 years) and short-term (1-3 years) outcomes perceived to have been achieved, representing contributory stages on the journey to achieving IET's aspirations. These groups then joined together to share and review the emergent findings, detailing both their perceived outcomes to date and long-term hopes for the initiative. The resulting ToC provided a framework for the subsequent research, informing and being further refined by the interviews, focus groups and community survey (see below), with participants being invited to critique the current version and make further suggestions.

\subsection{Semi-structured one-to-one interviews and focus groups with local stakeholders}

In total, twenty-four one-to-one interviews and two focus groups were conducted with 32 stakeholders. Initially, the oversight group and researchers co-determined a purposive sample (Stake, 2005) of key individuals involved in IET $(n=10)$. These were interviewed first to develop an understanding of the origins and development of IET and its three 'spinning plates'. They identified other key community members for interview from each of these plates and through subsequent snowball sampling (Patton, 2001), further stakeholders were interviewed: community (e.g. members of the IET community group and local council) $(n=6)$; business (local small business owners) $(n=4)$; and learning (e.g. the headmaster of the local primary school) $(n=4)$. To gain insights informed by interaction as well as individual perspectives (Wilkinson, 2011), focus groups were conducted with young people representing the community and7 learning plates $(n=3)$ and market holders representing the business plate $(n=5)$. There were no restrictions to participating in the interviews and the criteria for determining who to interview was primarily shaped by consensus - cross referencing names which were mentioned in different interviews with regards to who had been particularly involved in IET with regards to the particular 'spinning plate'. Both interview and focus group schedules explored stakeholder experiences and attitudes relating to IET, and examined perceptions concerning short- and mid-term impacts, enablers and challenges.

\subsection{Community survey}

A questionnaire survey was designed to explore awareness, attitudes and behaviours related to IET among the broader community in Todmorden. Where 
possible, the questions followed the same format as a previous study (Lee-Woolf, 2009 ) in order to provide comparative insight over time. After piloting and refinement, the survey was administered both online and face-to-face 'on the street'. The online survey was advertised primarily through online social networks, principally Todmorden-related Facebook community pages. Street interviews were conducted in the town centre across both working days and weekend days. A total of 320 residents participated in the survey. The survey used a mixture of closed and optional open questions in order to be appropriate for respondents with little or no knowledge of IE or food issues as well as accommodate more in-depth views.

Interviews and focus groups were audio-recorded, transcribed and subjected to thematic analysis using NVivo software. Analysis included cross-checking with community survey responses and the ToC model, to build understanding through discovering themes within the raw data and interpreting their implications in relation to the research aims (O'Leary, 2004). Secondary and tertiary themes were coded and grouped under primary themes.

Ethical approval was granted by the Universities' Ethics Committee. In writing up findings, quotes were anonymised to ensure confidentiality in the context of a closeknit community.

\section{Results}

\subsection{Overview}

Data drawn from the Theory of Change workshop, interviews, focus groups and the community survey indicate that changing landscapes by opening up public realm and other assets for food growing and community expression can be an important placemaking tool. The findings strongly suggest that IET has achieved positive social, economic and environmental impacts, through its focus on the 'three spinning plates' of community, business and learning that make up its overarching model. In turn, this model would appear to have informed a global movement and encouraged implementation in diverse contexts. IET has clearly enhanced the wellbeing of Todmorden as a 'place' and promoted the wellbeing of its community, at least in part through facilitating changed relationships of people with their locality. Whilst highlighting some cynicism and resistance to change, the findings point to a reputational gain for the town, linked to 'vegetable tourism' and an upward trend not only in local food production, but also in the purchase of locally-sourced food. IET has also developed understanding and skills and catalysed awareness of local and global sustainability concerns, fostering grassroots activism and engagement with policy and planning.

\subsection{Theory of Change}

The three 'spinning plates' strands of the ToC, community, business and learning, were brought together in the stakeholder workshop and subsequently refined using data from the survey, interviews and focus groups (Figure 2). The model presents a simplified representation of the key long-, medium- and short-term outcomes perceived to be pertinent to IET. It aims to illustrate stakeholders' understandings of the links between activities and outcomes whilst balancing the need to account for the complexity of interactions with the benefits of conceptual clarity. 


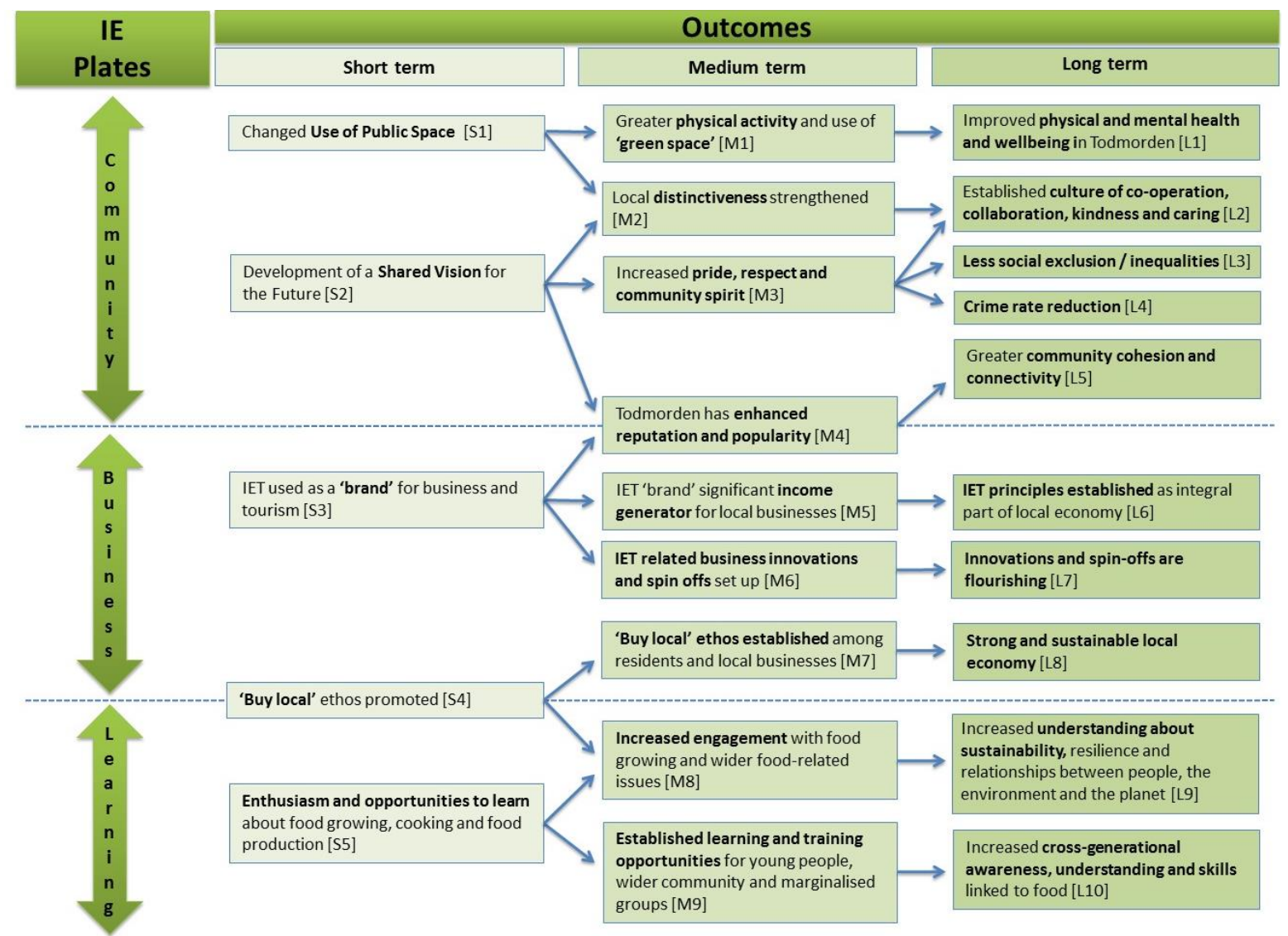

Figure 2: IET ToC Model

Among the key outcome pathways identified by the ToC is the perceived relationship between changes in the use of public space in the short term and a long-term positive impact on mental and physical health and wellbeing. In addition, the resulting distinctiveness is seen to lead to, among others, a culture of cooperation, collaboration, kindness and caring.

Qualitative data from the interviews and focus groups, and quantitative data from the community survey, are presented under primary themes corresponding to the three 'spinning plates' - community, business and learning outcomes - together with the additional theme 'enablers and challenges'.

\subsection{Community Outcomes}

The community survey indicated high levels of knowledge of and engagement with IET (see Table 2). Awareness of IET was almost universal, with $97.5 \%$ of participants being aware of Incredible Edible in Todmorden and nearly a third $(31.9 \%)$ having actively engaged with IET over the last 12 months. Comparison with the 2009 survey (Lee-Woolf, 2009), conducted two years after the establishment of IET, indicated a large increase in the proportion of residents consuming IET produce and a significantly deeper understanding of the aims of IET. This is despite there being similar levels of awareness and direct engagement with IET as a community group. 


\begin{tabular}{|l|c|c|c|}
\hline & $\begin{array}{c}\text { Percentage } \\
\text { of Positive } \\
\text { Responses }\end{array}$ & $\begin{array}{c}\text { Equivalent } \\
\text { data from } \\
\mathbf{2 0 0 9} \\
\text { study }\end{array}$ & $\begin{array}{c}\text { Change in } \\
\text { percentage } \\
\text { since 2009 }\end{array}$ \\
\hline $\begin{array}{l}\text { Are you aware of Incredible Edible in } \\
\text { Todmorden? }\end{array}$ & 97.5 & 89 & 8.5 \\
\hline $\begin{array}{l}\text { What do you understand its aims to be? } \\
\text { Increase the amount of food } \\
\text { grown locally } \\
\begin{array}{l}\text { Raise awareness of how to grow } \\
\text { food }\end{array}\end{array}$ & 73.9 & 68.6 & 5.3 \\
$\begin{array}{l}\text { Strengthen community } \\
\text { relationships }\end{array}$ & 64.5 & 11.2 & 58.9 \\
$\begin{array}{l}\text { Encourage people to eat more } \\
\text { fruit and veg } \\
\text { Change the appearance of the } \\
\text { town }\end{array}$ & 61.6 & 16.2 & 44.9 \\
$\begin{array}{l}\text { Reduce the environmental impact } \\
\text { of food } \\
\text { Become self-sufficient }\end{array}$ & 56.0 & 2.1 & 54.8 \\
\hline $\begin{array}{l}\text { Do you pick plants from the edible } \\
\text { growing beds/orchards in the town } \\
\text { centre? }\end{array}$ & 45.5 & 11.2 & 34.3 \\
\hline $\begin{array}{l}\text { Have you taken part in any activity } \\
\text { involving Incredible Edible over last 12 } \\
\text { months? }\end{array}$ & 31.9 & 30.5 & 1.4 \\
\hline
\end{tabular}

Table 2: Summary Results from Todmorden Community Survey

Respondents generally agreed that through the creation of propaganda gardening sites, IET has visibly and positively impacted the town and its landscapes. In the community survey, over half $(56.9 \%)$ identified the aim to 'change the appearance of the town'. During the interviews, examples were given of how the community had reclaimed and enhanced unused or derelict spaces, as well as securing permission to plant on verges and car parks, within schools and care homes, and at the police station, health centre and train station. Additionally, IET has catalysed wider visual improvements through public art.

The focus on using the public realm differently was understood to have changed people's perceptions of and relationships to their local environment, creating a greater sense of ownership and positivity:

That sense of place that is positive, allows a shift in mind-set in your relationship with the place...That, to me, is the most significant thing. (Participant \#3)

However, whilst there was widespread support for IET in terms of reclaiming public space, the community survey elicited some negative comments about its landscape impact, with concerns that some food-growing areas looked untidy or abandoned. 
The notion that IET had brought people together to improve the community permeated participants' stories, which were often filled with a sense of confidence and creativity and highlighted the importance of vision and innovation:

People coming together and thinking, "OK, we need to raise money for something or change something or create something." People are...thinking outside the box. (Participant \#2)

IET was seen to have helped build a shared sense of purpose for many residents. Food has not only become a focus in its own right and a means to bring people together to focus on community concerns, but also a vehicle to convey wider sustainability messages, engage people in discussions about key ecological challenges facing the planet, and encourage a 'think global, act local' ethos:

It's so important to our future, to start to think about our food... It's a communication tool, it's a 'breakdown barriers' tool, it's a lovely thing we share for fun and for love. But it's massively important to the future health and wellbeing of ourselves... [and] the planet. (Participant \#2)

Of participants in the community survey, $45.5 \%$ understood an aim of IET to be to 'become self-sufficient'.

As illustrated in Table 2, the community survey and comparative analysis with the 2009 study suggest that this ethos is understood by the community at large, with a clear broadening in appreciation of the relationship between growing food and wider place-based impacts such as the towns physical appearance, community relationships and the environmental impact of food consumption.

Interview participants viewed increased physical activity (e.g. through horticultural work) as an important benefit of IET, linked to enhanced health:

Improved physical and mental wellbeing for Todmorden, I think so, people feel better. If you get people out doing a little bit of exercise, a bit of walking, a bit of digging... (Participant \#13)

They also highlighted the wellbeing impacts of the 'Incredible Todmorden Way' walking route:

The minute you come into the town on the train, you've hit the green route... [there are] health benefits there. (Participant \#13)

Whilst growing food and creating edible landscapes were understood to be key to IET, the initiative was generally perceived to go beyond this, encouraging positive values such as kindness - with the rhetoric being practically applied through sharing food, cooking for people in need and connecting with others. Indeed, $64.5 \%$ of community survey respondents recognised 'strengthened community relationships' as an aim of IET. This ethos was seen to have enhanced local distinctiveness and contributed to change, in turn shifting attitudes:

There's a lot of northern towns... where there isn't anything like this... and the High Street's... deadly boring and...samey. And then suddenly, you come to...Todmorden and there's this wonderful community, there's people who are really trying to make a better world, you know, their little corner. (Participant \#27) 
Linked to this, interview data suggested that people are proud to be associated with IET and its achievements, aware of a new-found 'feel good' factor in a town that had been in decline. Alongside its contribution to improving Todmorden's appearance, participants noted a perceived reduction in vandalism:

You can attribute it to... ownership...this is our town and... we're not going to smash it up...If you live here, look after it, treat it right, treat it with respect and be part of it...And yes...crime did go down. I think [IET] helped, I think it was a contributory factor. (Participant \#13)

Another example cited for IET fostering 'community spirit' was when the town was flooded in 2012 and 2015. IET volunteers aided victims by providing food and assistance:

That's what it's about, resilience. The floods were...a gift to us, because we're a natural group that can respond. We've got communication systems, we've got devoted people, passionate community... (Participant \#9)

Similarly, the community survey suggests a common feeling that IET has transformed Todmorden for the better, in terms of both landscape and communitybuilding. Alongside this, interview participants highlighted IET's contribution to outsiders' improved perceptions of the town, which in turn have improved residents' perceptions:

We are a town that has its positiv[ity] reflected back to it...and people may not know why that's happened but there is now a difference... people comment a lot about how... people have heard of Tod when they hadn't before.

(Participant \#3)

This had also created challenges for the local community, notably concerns about IET's role in Todmorden leading to potential gentrification in the area:

There's more and more people wanting to move to the area...it becomes impossible for the person to afford...housing [which leads to] resentment: "well we can't afford to live here now, I'm going to have to move somewhere else that's cheaper whilst you take my house in my town that I was born and brought up in". (Participant \#26)

\subsection{Business Outcomes}

IET's support for local producers was principally articulated through the use of IETbranded market signs and an increase in locally-sourced food in shops and on menus. Although interview data suggested historical tensions with the market and local reluctance to embrace change, IET was also regarded by others as vital to the market's survival:

To continue as we were [the market] would have died a death. So whether you like it or not, maybe you should just listen a bit more and look at what Incredible Edible Todmorden are trying to do. (Participant \#26)

Whilst some survey respondents suggested that more could be done to involve local businesses, local producers spoke of the advantages of being associated with IET: 
Joining Incredible Edible does help us....because we're standing out as being a local producer...[IET tour organisers] do stop off in the market and they want to buy something local. (Participant \#24)

There has also been an increase in 'vegetable tourism', with Todmorden's visitor centre reporting IET as the most frequent attraction for international visitors, and second for British visitors:

Most of the foreign visitors...the only two words that they seemed to know are 'Incredible Edible', how famous. (Participant \#26)

As noted above, IET was widely regarded as being a positive influence for Todmorden and how it is perceived. From the 'business' perspective, IET's media presence and 'vegetable tourism' has had global reputational impact:

I think Incredible Edible has done amazing things to put Todmorden on the map. Suddenly...it's a place, where...things happen. It's a destination town, people go to Todmorden to see a thing, to...see how Incredible Edible do it. (Participant \#27)

Todmorden's increased desirability as a place to reside was thought to be linked to the economic impact of IET's presence. Whilst it was acknowledged that there may be a degree of myth-making, this does not detract from the perceived economic impact:

It's got a kind of subculture...'the good life place'. Whether it's true or not, it's good for the town, it's good for business, it's good for property. (Participant \#9)

The establishment of two 'spin-off' social enterprises - the Incredible AquaGarden and Incredible Farm - was highlighted as an important outcome. Whilst they have their own economic imperative, both are strongly committed to supporting local communities:

We're interested in top-slicing whatever we earn...so that we can help people who can't afford to pay for a course. [We're] just trying to recycle it back...we were created for local people...this is what needs to be replicable, this localism stuff. (Participant \#3)

Linked to motivations related to carbon reduction, animal welfare, ecological sustainability and resilience, an important focus of IET has been increased awareness of the value of buying locally-sourced produce:

I think there's definitely been a positive impact on...local food, the understanding of the importance of it. (Participant \#7)

Indeed, in the community survey, the most commonly recognised aim of IET was to 'increase the amount of food grown locally' (73.9\%). The survey also indicated that purchasing local food has increased since the 2009 study and is higher than the national average (Morley, Farrier and Dooris, 2017). With customers wanting more provenance over food, it has become a norm for market-traders to be asked about origins of their produce:

I think [IET's]...made people aware of buy local....and yes, it's made people aware that they're better off buying 'what you know'. (Participant \#28) 
Alongside this optimism, the community survey highlighted challenges and constraints in making 'buy local' a reality: whilst some expressed enthusiasm, others commented that availability and expense remained key challenges.

\subsection{Learning Outcomes}

In addition to providing volunteering opportunities that enhance food growing skills IET has prioritised community learning through the provision of educational information at growing sites. Whilst viewed as effective by many, some survey respondents suggested that this is failing to reach certain sections of the community or to communicate clearly.

Although the community survey indicated strong community engagement with IET including through harvesting produce from its edible landscapes, it also revealed some reticence to pick and eat food. Although nearly half (44\%) had picked food from public spaces, nearly a quarter (23\%) of respondents felt uncomfortable about doing so, whilst $17 \%$ cited concern about contamination from sites being close to roads as a concern.

IET appears to have impacted particularly strongly on young children, increasing knowledge about where food comes from and about nature and the environment. It was suggested that the visibility of edible landscapes has led to a shift in local children's regard for food growing, normalised as part of everyday life:

Children walking past those beds in the street going to school are learning without realising it, because they're seeing vegetables growing...Because when we first started, [the] little kids didn't understand that vegetables came out of the dirt. (Participant \#10)

Whilst those interviewed recognised that children tend to learn more readily than adults, they also highlighted the importance of life-long learning, which may lead from an increased knowledge about food to an awareness of local community assets. This relationship was recognised by community survey respondents, with $70.1 \%$ identifying to 'raise awareness of how to grow food' as an aim of IET.

Although strongly focused on local issues, IET also seeks to develop the community's world-view and achieve a greater understanding of and engagement with macro-level issues, with $55 \%$ of survey respondents understanding 'reduce the environmental impact of food' to be an aim of IET. Alongside scepticism about selfsufficiency rhetoric, it was clear that IET sought to engage with key sustainability and health challenges:

That is very much where...Incredible Edible will come in...we have a wonderful natural environment, and we want to have a...sustainable future around things like our air quality, our transport and our rates of obesity and health and wellbeing. (Participant \#14)

IET was seen to have empowered 'already-aware' individuals to take small steps:

I find climate change and all of that...huge...issues that you feel, individually, quite powerless about... You need somehow to get people to [believe they can make a difference]... This 'small action thing' appealed to me. (Participant \#7)

Promoting cooking skills is also an important component of IET's approach. 
We give out recipes whenever we can and encourage people to think about cooking, rather than buying ready-meals. And show them that you can grow things quite simply, even if you've not got a lot of space, and you can actually [cook and] eat what you grow and do it cheaply and easily. (Participant \#21)

Schools were an obvious means to reach young people, simultaneously offering outdoor space for food growing. This has changed the appearance of grounds as well as influencing how they teach about food:

There's a lot more 'hands on' with the schools than there's ever been before. It was fantastic seeing the veg. patches coming up in the junior school and high school.... they had loads of planters in their playgrounds, made out of old tyres and stuff. (Participant \#15)

This focus has been strengthened and developed through intergenerational cooking classes, encouraging parents to learn alongside children. IET has also worked with families in disadvantaged communities to build understanding of food growing and cooking, and encourage healthier eating. This activity is no doubt reflected in the community survey, where $61.6 \%$ of respondents recognise IET as aiming to 'encourage people to eat more fruit and vegetables'.

\subsection{Enablers, Challenges and Wider Development}

In addition to exploring perceived outcomes, the data offered insights into the broader dynamics that have influenced of IET's development. A number of enabling factors were identified that relate to Todmorden as a place. Whilst its 'peripheral' geographical location on the edge of two large counties (Yorkshire and Lancashire) and distance from the town of Halifax (the 'seat' of local government decisionmaking) was viewed as challenging, participants also saw this as contributing to the town's distinctiveness, cohesiveness and drive:

Where we're situated, we're at the far end of Calderdale [valley], so we get left out or the money seems to only reach certain parts...So that's why we say 'right, well if they won't do it, we'll do it ourselves'. (Participant \#26)

Respondents repeatedly alluded to the inspirational and charismatic personalities of IET's co-founders, seen to have engendered a culture of enthusiasm and proactivity. The 'spinning plates' model was largely endorsed as a powerful metaphor and understood to underpin IET's distinctiveness and success, although comment was made about the 'conformist' nature of using a model.

Although interview participants were overwhelmingly positive about IET's development and impact, largely through bottom-up activism, they also highlighted the importance of forging external relationships enabling advocacy and influence through policy and planning:

It would be very, very difficult... without a friendly relationship within the council...They would have come across much more conflict in lots of little practical things. (Participant \#11)

Alongside widespread enthusiasm, there was resistance to change from some longer-term residents, perhaps reflecting tensions with perceived 'newcomers': 
It's like, "well we've lived here all our life, we don't want that fancy new stuff"...At least they [IET] have got off their backsides and done something about improving the area. (Participant \#26)

Although there was a general sense that IET has helped break down barriers and bring people together, some questioned the breadth of its appeal:

[On] Todmorden chat forums and Facebook, it's only a few people who actually get it, the rest of them think, "what are all these weirdos doing planting peas in the police station?". (Participant \#24)

Interviews and focus groups highlighted the strength of IET's cross-generation activities, alongside challenges in engaging teenagers and young adults.

Additionally, IET has sought to move beyond its white middle-class base, forging partnerships with housing organisations and minority ethnic groups.

IET's evolution into a 'family' of connected organisations (IET, IE Network, Incredible Farm, Incredible AquaGarden) seemed to make sense to those actively involved, reflecting individuals' diverging priorities and emphases - for example, between focusing within Todmorden and focusing externally, and between prioritising community-led self-reliance and securing leadership, funding and support from organisations and policy-makers. However, others perceived this fragmentation to have resulted in 'silo' working and weakened coherence. In this regard, several stakeholders acknowledged that IET has been borne out of, and thrived, on differences, and highlighted how the innovative, inspirational and charismatic leadership characterising IET goes hand-in-hand with creative tensions:

Amazing things happen because of amazing people, and amazing people are quite difficult! (Participant \#11)

A key question is the extent to which the IE model, as developed and applied in Todmorden, is reproducible as a community-led framework for improving social, economic and environmental wellbeing. Whilst linking IET's success to the particular enabling factors identified above, participants felt that there was enormous potential for the approach to be implemented elsewhere, as evidenced by its 'viral' spread. They also noted the danger of outsiders viewing Todmorden as a place uniquely primed for IE to flourish, without recognising the challenges faced. Furthermore, it was argued that, whilst important for the movement to retain coherence, IE initiatives must be able to 'start small' - linking incremental change to a bigger vision of what's possible longer-term - and take control of their own identity, with flexibility to evolve as they wish, within their particular contexts:

You have to let it grow in whatever way is right for that particular community or that particular environment. (Participant \#2)

\section{Discussion}

This paper has reported findings exploring the social, economic and environmental impacts of the IE model as applied in Todmorden. A mixed methods approach was adopted, drawing on mainly qualitative data generated from a ToC workshop, community survey, interviews and focus groups. Reflecting wider literature (Taplin and Clark, 2012; Taplin, Clark, Collins and Colby, 2013), the final ToC, refined iteratively through the process of data collection, provided a valuable framework to 
guide the evaluative research. A further strength is that it can, over time, be revisited to check whether IET is 'on course' to achieve its long-term vision.

Reflecting the experience of other community-based research (Resnik and Kennedy, 2010), a key challenge was to isolate 'real' impact from subjective appraisals - in this case drawn from people close to the IET 'cause'. Although views elicited across all data collection strands were largely consistent and overwhelmingly positive, it was important that the survey complemented the interviews and focus groups by capturing voices not strongly engaged with, or in opposition to, IET.

There can be little doubt that IET has impacted significantly on the town. As the survey illustrated, there have been upward trends in awareness, engagement and particularly understanding of the aims of IET over time. This is a testament to the drive and passion of those involved and to their success in visibly shaping Todmorden's landscape though the IE model. The ToC framework mapped perceived long-term, medium-term and short-term impacts, using the three 'spinning plates' of community, business and learning. Focusing primarily on the short-term and medium-term, the interview, focus group and survey data further elucidated this. Reflecting wider literature on community food growing (Barron, 2017; Çelik, 2017; Certomà and Tornaghi, 2015; Coles and Costa, 2018; Hardman, Adams, Barker and Beesley, 2019; Purcell and Tyman, 2015; Veen et al., 2016), the identified impacts were wide-ranging. Social impacts included changed relationships with the locality, strengthened local distinctiveness, a shared sense of pride and togetherness, and enhanced physical and mental health. Economic impacts included the use of the IET 'brand' as an income generator for local businesses and tourism, IET-related business spin-offs and an established 'buy local' ethos. Environmental benefits included enhanced local landscapes and an increased understanding of wider issues related to food, ecology and sustainability.

Whilst IET remains best known for its tangible influence on the town's public (and 'appropriated private') realms through the creation of edible landscapes, the breadth of these interconnected impacts point to the important role of space and place in enhancing social, economic and environmental wellbeing. The ambitious long-term outcomes included in the ToC and signalled in subsequent data collection suggest confidence in the IE model. They also confirm IET's commitment to connect local place-based action with large-scale challenges facing societies and the planet, pointing to successes in developing a 'think global, act local' ethos - an early aspiration of key actors (Smales and Warhurst, 2016).

It should be noted that it proved challenging to explore the positive impact of IET on health and wellbeing. Representatives from the town's health centre were unsuccessfully sought for interview, and town level statistics for health outcomes are limited. The interview and focus group data, however included multiple explicit references to increased levels of exercise and perceived impacts on wider physical and mental health. This was frequently related to the ways in which IET had created a shared sense of purpose and togetherness, promoted a culture of kindness and connectedness, improved environments, made people proud to live in Todmorden and strengthened community cohesion, all of which are outcomes that can all be viewed as health determinants (Dahlgren and Whitehead, 1991; Barton and Grant, 2006). 
Whilst the ToC would seem to provide an accurate representation of IET's impacts and longer-term goals, it can also be viewed as idealised. Issues related to personalities and IET's organisational evolution were recurrent. As reflected in previous literature (Paull, 2013), IE in Todmorden is complex and, for some, confusing. It has evolved into a series of interrelated organisations led by individuals with their own priorities, all operating within the IE framework. As Froggett (2014: 242) notes, the arena characterised by grassroots localism, voluntarism and civic action "is by no means a conflict-free arena and tensions may be intensified by...the flat structures of democratic participatory organisations." Whilst complexity may strengthen the IE model in terms of resilience and reach, it also presents challenges.

A divergence between internal and external focus and between self-reliance and external resource reliance reflects deeper distinctions in social and environmental movements, concerned with challenging or subverting neo-liberal forces (Certomà and Tornaghi, 2015). For example, whilst some initiatives emphasise 'grassroots' activism mobilising 'bottom-up' community action and largely reject engagement with 'top-down' bodies, others prioritise 'political' activism seeking wider societal change through utilising statutory planning frameworks and securing policy-into-action commitments from local, regional and national governance bodies (Hardt, 2013; Patrick, Dooris and Poland, 2016). These distinctions also resonate with current discourse about the appropriateness of asset-based community development. Whilst widely championed as progressive, this has been subject to criticism, viewed as a convenient neo-liberal approach to mobilise 'free' resources in a time of austerity (Friedli, 2012).

Alongside largely positive attitudes, the data highlighted dissenting voices, cynicism and a vein of resistance to change within the town - all of which have been noted in other research, along with discussions concerning the significance of 'incomer' status within established communities (Allen, Clement and Prendergast, 2014). Most of those actively involved in IET hail from beyond Todmorden, although many have been resident in the town for decades. Overall, though, it was apparent that the town has welcomed IET. In common with other community projects (Onyx and Leonard, 2011), visionary and driven leadership from key individuals appears to have been instrumental to its success.

IET has also successfully challenged prevailing planning policy discourses, which has led to the inclusion of supporting policies in the Local Plan, which is the overarching planning vision for the council and due to come into force in 2020. The plan includes the policy that 'All new residential developments... shall include gardens or communal areas... to support household food production. Furthermore all developers are encouraged to explore ways to incorporate food growing into landscaping schemes and the spaces around their developments' (Calderdale Council, 2018).

The role of 'place' has also been important. In terms of location, Todmorden was described in interviews as a frontier town, on the border between two large counties, located in a small valley in the Pennine Hills and with a history of doing things its own way:

"We've always had a kind of 'get on and do it' attitude... where we're situated...we get left out...So we very much sometimes feel that...we're a bit 
out on a limb. So that's why we take advantage of saying 'right, well, if they won't do it, we'll do it ourselves." (Participant \#26)

Its history is understood to have influenced today's activism (The Guardian, 2018), whilst the reluctance to embrace change apparent in the research findings appears to have emerged in part from Todmorden's socio-economic and geographical isolation and a concern to defend its traditional character (Klein, 1967). This accords with recent studies exploring the concerns of other rural towns and reflects wider national-level insecurities about identity (Kerrigan, 2018). Paradoxically, although an 'outsider' distinctiveness has helped IET flourish, it has also made some parts of the community less flexible and open to IET.

More positively, findings suggest that IET has contributed to sustainable placemaking (Franklin and Marsden, 2015:954) and place-keeping Dobson (2014), linked to strengthened distinctiveness and a shared sense of community, purpose, ownership and pride, echoing other studies (Egli, Oliver and Tautolo, 2016). Todmorden's increased 'beautification' and community vitality through edible landscapes has enhanced its appeal to outsiders and, as documented in other urban gardening initiatives, reputational gain tends to catalyse gentrification (Marche, 2015; Wolch, Byrne and Newell, 2014). Although the study did reveal some anxieties about IET causing gentrification in Todmorden, there was insufficient evidence to assert that this is actually the case, and recent studies have argued that to suggest urban food growing initiatives are able to do this overestimates the amount of influence they alone can have when so many other factors are involved (Håkansson, 2018). However, it is important to acknowledge that this process of beautification, which appears to have exacerbated schisms and led to concerns from some long-term residents, can have negative as well as positive impacts and is an important consideration when examining the efficacy of the IET model.

The study affirmed that reclaiming and reconfiguring the community's relationship with the public realm, borne from propaganda gardening, was a central feature of IET. Echoing other IE initiatives (Hardman et al., 2018), although IET started with 'illicit' guerrilla gardening, it quickly went on to legitimise its activities by negotiating with organisations such as Calderdale Council, the local health centre and the police station - securing permission to use land for food production and finding creative ways of replacing what Smales and Warhurst (2016: 235) call "the aesthetically dead hand of so-called 'municipal planting'." This appears congruent with democratization of space and the 'new commons' movement, concerned with communal management of land and resources as a form of resistance to private ownership and globalization (Brown, Kraftl, Pickerill and Upton, 2012; Certomà and Tornaghi, 2015). However, this space remains contested, with some local disquiet from people bothered by the 'untidy' appearance of vegetable patches out-of-season. This mirrors other studies, which suggest that disputes over use of public spaces are inevitable and, to an extent, necessary (Holland, Clark, Katz and Peace, 2007).

Achieving cultural change and a shift of 'mind-set', by getting people to think differently about food and their relationship to their environment, has been encouraged by the increased profile of locally-sourced food and an understanding that healthy fresh food can be inexpensive. Linked to this, IET appears to have had some degree of success in embedding the 'glocal' (Brooks and Normore, 2009), making links between local community-based action and global concerns. Food has been used as a focus in its own right, as a means of engaging and connecting 
community (partly through visibility and changed landscapes), and as a vehicle for catalysing awareness of and action for global sustainability, linking place, people and planet. This has been inadvertently assisted by two incidences of flooding, which have highlighted the effects of climate change on the local community (The Guardian, 2015). Reflecting on the imperative of adaptive capacity and transformation in the context of such socio-ecological challenges, Petrescu et al. (2016) suggest that IE, along with the Transition Movement (Hopkins, 2010), mobilises resilience strategies that strengthen local communities and challenge dominant economic and political systems. Noting the lack of research exploring links between grassroots resilience initiatives and the 'new commons' movement discussed above, they urge local authorities to actively facilitate co-productive approaches through local plans.

A question posed by the findings is the extent to which the Todmorden IE model can be applied elsewhere. Replicability of actions within the town was identified as a key characteristic early on (Paull, 2013). The IE movement has spread widely within the UK and across the globe, with the IE website receiving up to 10,000 hits per day (Thompson, 2012). However, whilst the global spread of IE, documented to have reached more than 500 projects worldwide (The Guardian, 2018), shows a commitment to the IE model 'in principle', it is unknown how many have applied it in practice, implementing the three 'spinning plates' in an holistic way and achieving a similar range of impacts to IET. Indeed, it is questionable whether some impacts highlighted by this study could have the same potency in places that are following rather than 'trailblazing'. For example, the creation of an effective 'brand for business and tourism' has been greatly assisted by the novelty of being the birthplace of IE, attracting the buy-in of local businesses and making Todmorden a go-to destination. Moreover, fostering 'enhanced reputation and popularity' derives in part from the well-developed media literacy of key IET stakeholders (Paull, 2013) combined with continued media thirst for feel-good stories focused on the locality that has inspired a global movement (The Guardian, 2018). As intimated by the findings, it might therefore be more accurate to understand IE as reproducible in terms of its broad vision, ethos and community-led bottom-up approach - a broad 'church' comprising multiple initiatives that flourish by finding their own distinctiveness in relation to place and context (Schifferes, 2014).

\section{Conclusion}

More than a decade after its establishment, IET remains one of the most visible and influential examples of urban food movements, having spawned an international network of similar groups under the IE umbrella with global reach (Hardman, Adams, Barker and Beesley, 2019). As Dobson (2014:129) argues: "It merits attention not only because of its high profile, but also because it seeks to join up the various strands of environmentalism, economic development and food justice within a particular locality, and has changed the reputation and profile of that locality in the process."

This study had two aims: to evaluate the social, economic and environmental impacts of IET on the local community; and to assess its wider potential as a community-led framework for improving social, economic and environmental wellbeing. In relation to the first, whilst framed using the three 'spinning plates' model, the themes depicted in the ToC and emerging from the interviews, focus groups and survey revealed generally positive outcomes pertaining to perceptions of 
social, economic and environmental wellbeing. Regarding the second aim, the study found that, whilst appreciating Todmorden's own particular enabling factors, participants perceived that the IE model could be successfully, but flexibly, implemented in other contexts - as evidenced by the movement's global viral spread.

The case of IET suggests that changing landscapes by opening up public realm and other assets for food growing and other forms of community expression can be an important and holistic place-making tool - promoting health, wellbeing, ecological sustainability, distinctiveness and belonging. This paper adds value to the academic debate by reporting on a study that, for the first time, undertook a comprehensive multimethod evaluation focused on the economic, social and environmental impacts of IET in relation to its 'spinning plates' model. The findings present a strong argument that IET has nurtured an authentic 'sense of place' (Silberberg et al., 2013:2) in Todmorden for some of its residents. This may have important implications for public policy, particularly with regards to: the growing evidence base of the value of horticulture (e.g. for social prescribing); enabling community food growing initiatives to harness assets within the public realm (e.g. unoccupied or derelict land); and creating and facilitating enabling environments in which self-starting community groups can interact and flourish. In order to understand these relationships better, there is a need for multi-site and comparative model studies to explore the importance of contexts and examine the stories and impacts of different initiatives and models.

\section{Acknowledgements}

This work was supported by Nisa Retail Ltd. and the Ashden Trust. We would like to thank those involved in Incredible Edible Todmorden, Incredible Edible Ltd. and Todmorden's wider community for participating in the research project. We are also grateful to Mags Adams for commenting on an earlier draft.

\section{References}

Allen, M., Clement, S. and Prendergast, Y. (2014) A 'can-do' approach to community action: what role for risk, trust and confidence? York: Joseph Rowntree Foundation. https://www.jrf.org.uk/report/\%E2\%80\%98can-do\%E2\%80\%99-approachcommunity-action-what-role-risk-trust-and-confidence (accessed 16 July 2019)

Barron, J. (2017) Community gardening: cultivating subjectivities, space, and justice. Local Environment, 22(9): 1142-1158.

Barton, H. and Grant, M. (2006) A health map for the local human habitat. Perspectives in Public Health, 126(6): 252-253.

Brooks, J. S. and Normore, A. H. (2009) Educational Leadership and Globalization: Literacy for a Glocal Perspective. Educational Policy, 24(1): 52-82.

Brown, G., Kraftl, P., Pickerill, J., and Upton, C. (2012) Holding the future together: towards a theorisation of the spaces and times of transition. Environment and Planning A, 44, pp. 1607-1623 DOI: 10.1068/a44608

Calderdale Council (2018) Calderdale Local Plan Publication Draft 2018. http://calderdale- 
consult.limehouse.co.uk/portal/planning services/lpp18//pp18?pointld=4796887 (accessed 16 July 2019)

Çelik, F. (2017) The importance of edible landscape in the cities. Turkish Journal of Agriculture - Food Science and Technology, 5(2), 118-124.

Certomà, C. (2011) Critical urban gardening as a post-environmentalist practice. Local Environment, 16(10): 977-987. DOI: 10.1080/13549839.2011.592181

Certomà, C. and Tornaghi, C. (2015) Political gardening. Transforming cities and political agency. Local Environment, 20(10): 1123-1131. DOI:

10.1080/13549839.2015.1053724

Clarke, P. (2010) Incredible Edible: how to grow sustainable communities. FORUM, 52(1): 69-76.

Coles, R. and Costa, S. (2018) Food growing in the city: Exploring the productive urban landscape as a new paradigm for inclusive approaches to the design and planning of future urban open spaces. Landscape and Urban Planning, 170: 1-5.

Connell, J. and A. Kubisch (1998) 'Applying a Theory of Change Approach to the Evaluation of Comprehensive Community Initiatives: Progress, Prospects and Problems', in K. Fulbright-Anderson, A. Kubisch and J. Connell (eds) New Approaches to Evaluating Community Initiatives, Vol. 2, Theory, Measurement, and Analysis. Washington, DC: Aspen Institute.

Dahlgren G. and Whitehead, M. (1991) Policies and strategies to promote social equity in health. Stockholm: Institute for Future Studies.

https://core.ac.uk/download/pdf/6472456.pdf (accessed 16 July 2019)

Dempsey, N., Smith, H. and Burton, M. (Eds.) (2014) Place-keeping: Open space management in practice. Abingdon: Routledge.

Denzin, N.K. and Lincoln, Y.S. (2008) The Landscape of Qualitative Research (3 ${ }^{\text {rd }}$ ed.) Thousand Oaks, CA: Sage.

Dobson, J. (2014) Achieving food equity: Access to good local food for all. Journal of Urban Regeneration and Renewal, 8(2): 124-134.

Dobson, J. (2017) From 'me towns' to 'we towns': activist citizenship in UK town centres. Citizenship Studies, 21(8): 1015-1033.

Egli, A., Oliver, M. and Tautolo, E. (2016) The development of a model of community garden benefits to wellbeing. Preventive Medicine Reports, 3: 348-352.

Franklin, A. and Marsden, T. (2015) (Dis)connected communities and sustainable place-making, Local Environment, 20(8), 940-956.

Fincher, R., Pardy, M. and Shaw, K. (2016) Place-making or placemasking? The everyday political economy of "making place". Planning Theory \& Practice, 17:4, 516-536.

Friedli, L. (2013). 'What we've tried, hasn't worked': the politics of assets-based public health. Critical Public Health, 23(2): 131-145. 
Froggett, L. (2014) Community, Communitarianism and Displacement Anxiety. In M. Fotaki and K. Kenny (Eds.) Psychosocial and Organisation Studies: Affect at Work, pp.241-262, London: Palgrave.

Gascon M., Triguero-Mas M., Martínez D., Dadvand P., Forns J., Plasència A. and Nieuwenhuijsen J.M. (2015) Mental health benefits of long-term exposure to residential green and blue spaces: A systematic review. International Journal of Environmental Research and Public Health,12: 4354-4379.

Gieryn. T.F. (2000) A Space For Place in Sociology. Annual Review Sociology, 26: 463-96

The Guardian (2015) Calderdale flood victims survey the damage: 'I can't go through this again'. Helen Pidd and Nigel Bunyan, Sun 27 Dec 2015.

https://www.theguardian.com/environment/2015/dec/27/calderdale-flood-victimssurvey-the-damage-i-cant-go-through-this-again (accessed 16 July 2019)

The Guardian (2018) Incredible Edible: Yorkshire town's food-growing scheme takes root worldwide. Naomi Larsson Wed 9 May 2018, last modified on Tue 14 Aug 2018. https://www.theguardian.com/world/2018/may/09/incredible-edible-yorkshire-townsfood-growing-scheme-takes-root-worldwide (accessed 16 July 2019)

Håkansson, I. (2018) The socio-spatial politics of urban sustainability transitions: Grassroots initiatives in gentrifying Peckham. Environmental Innovation and Societal Transitions, 29: 39-46.

Hardman, M., Chipungu, L., Magidimisha, H, Larkham, P.,Scott, A. and Armitage, R. (2018) Guerrilla gardening and green activism: Rethinking the informal urban growing movement. Landscape and Urban Planning, 170: 6-14.

Hardman, M., Adams, M., Barker, M. and Beesley, L. (2019) 'Food for all? Critically evaluating the role of the Incredible Edible movement in the UK'. In: Certomà, C., Noori, S. and Sondermann, M. (Eds.) Urban Gardening and the Struggle for Social and Spatial Justice, pp.139-153, Manchester: Manchester University Press.

Hardt, E. (2013). In Transition: The Politics of Place-based, Prefigurative Social Movements. Dissertations. 744.

http://scholarworks.umass.edu/open_access_dissertations/744 (accessed 16 July 2019).

Holland, C., Clark, A., Katz, J. and Peace, S. (2007) Social interactions in urban public places. Joseph Rowntree Foundation/The Open University. Bristol: The Policy Press.

Hopkins, R. (2010) The transition handbook: from oil dependency to local resilience. Critical Public Health, 20(3), White River Junction, VT, Chelsea Green. Index of Multiple Deprivation (2015) Index of Multiple Deprivation, London: Ministry of Housing, Communities and Local Government.

IEN (2019) Incredible Edible Network, https://www.incredibleedible.org.uk/ (accessed 16 July 2019)

Kerrigan, N.A. (2018) A Threatened Rural Idyll? Informal social control, exclusion and the resistance to change in the English countryside. Vernon Press. 
Klein, D. (1967) Some notes on the dynamics of resistance to change: The defender role, in G. Watson (Ed.) Concepts for Social Change. Washington, DC: National Training Laboratories NEA, for the Cooperative Project for National Development 1967: 31.

Lee-Woolf, C. (2009). A critical evaluation of the contribution that community-based action makes to sustainable development in the UK food system. Unpublished Masters Thesis. London: Centre for Environmental Policy, Imperial College.

MacGillivray, B.H. and Franklin, A. (2015) Place as a boundary device for the sustainability sciences: Concepts of place, their value in characterising sustainability problems, and their role in fostering integrative research and action. Environmental Science \& Policy, 53: 1-7.

Marche, G. (2015) What Can Urban Gardening Really Do About Gentrification? A Case-Study of Three San Francisco Community Gardens. European Journal of American Studies, Special Double Issue: The City, 10-3, 2015.

https://journals.openedition.org/ejas/11316 (accessed 16 July 2019)

Marovelli, B. (2019) Cooking and eating together in London: Food sharing initiatives as collective spaces of encounter. Geoforum, 99 (February 2019): 190-201.

Morley, A., Farrier, A and Dooris, M. (2017) Propagating Success? The Incredible Edible Model: Final Report. University of Central Manchester, Preston/Manchester Metropolitan University.

O'Leary, Z. (2004) The essential guide to doing research. London: Sage.

Office for National Statistics (ONS) (2011a) 2011 Census: Population and Household Estimates for Small Areas in England and Wales. Newport: ONS.

Office for National Statistics (ONS) (2011b) Neighbourhood Statistics. Newport: ONS.

Office for National Statistics (ONS) (2015) Population Estimates for UK, England and Wales, Scotland and Northern IrelandL mid-2015. Newport: ONS.

Onyx, J. and Leonard, R.J. (2011) Complex systems leadership in emergent community projects. Community Development Journal, 46(4):493-510.

Patrick, R., Dooris, M. and Poland, B. (2016) Healthy cities and the transition movement: converging towards ecological well-being? Global Health Promotion, 23(Suppl. 1): 90-93.

Paull, J. (2011) Incredible Edible Todmorden: Eating the street. Farming Matters, September 2011: 28-29.

Paull, J. (2013) Case study 10. 'Please pick me': How Incredible Edible Todmorden is repurposing the commons for open source food and agricultural biodiversity. In J. Fanzo, D. Hunter, T. Borelli and F. Mattei (Eds.) Diversifying food and diets. Using agricultural diversity to improve nutrition and health. Abingdon: Earthscan, 336-345.

Patton, M.Q. (2001) Qualitative research \& evaluation methods (3 ${ }^{\text {rd }}$ ed.). Thousand Oaks, CA: Sage.

Petrescu, D., Petcou, C. and Baibarac, C. (2016) Co-producing commons-based resilience: lessons from R-Urban, Building Research \& Information, 44(7), 717-736. 
Purcell, M. and Tyman, S. (2015) Cultivating food as a right to the city, Local Environment, 20(10), 1132-1147.

Resnik, D.B. and Kennedy, C.E. (2010) Balancing Scientific and Community Interests in Community-Based Participatory Research. Accountability in Research, July 2010; 17(4): 198-210. doi:10.1080/08989621.2010.493095.

Schifferes, R. (2014) Measuring your social impact: Community food projects in action. London: RSA Action and Research Centre.

Silberberg, S., Lorah, K., Disbrow, R. and Muessig, A. (2013). Places in the making: How place-making builds placemaking and communities. Boston: Massachusetts Institute of Technology.

Smales, L. and Warhurst, P. (2016) Sustainable urban design. In M. Dastbaz, I. Strange and S. Selkowitz (Eds.) Buiilding sustainable futures: Design and the built environment. Cham, Switzerland: Springer International Publishing, 229-245.

Stake, R. (2005) Qualitative case studies. In N. K. Denzin and Y. S. Lincoln (Eds.), The SAGE handbook of qualitative research ( $3^{\text {rd }}$ ed.). Thousand Oaks, CA: Sage.

Sustainable Food North West Research Collaboration https://susfoodnorthwest.org.uk/ (accessed 16 July 2019)

Taplin D. and Clark, H. (2012) Theory of Change Basics. A Primer of the Theory of Change. New York: Act Knowledge. http://www.theoryofchange.org/wpcontent/uploads/toco library/pdf/ToCBasics.pdf (accessed 16 July 2019).

Taplin, D, Clark, H, Collins, E and Colby, D. (2013) Technical Papers: A Series of Papers to support Development of Theories of Change Based on Practice in the Field. New York: Actknowledge and The Rockefeller Foundation.

http://www.actknowledge.org/resources/documents/ToC-Tech-Papers.pdf (accessed 16 July 2019).

Thompson, J. (2012) Incredible Edible - social and environmental entrepreneurship in the era of the 'Big Society'. Social Enterprise Journal, 8(3): 237-250.

Trivelli, L. (2013) Final report on Incredible Edible Todmorden. Pisa: University of Pisa.

Veen, E., Bock, B. Van den Berg, W., Visser, A. and Wiskerke, J. (2016) Community gardening and social cohesion: different designs, different motivations. Local Environment, 21(10): 1271-1287.

Warhurst, P. and Dobson, J. (2014) Incredible! Plant veg; grow a revolution. The story of Incredible Edible Todmorden. Pisa: University of Pisa.

White. J.T. and Bunn, C. (2017) Growing in Glasgow: Innovative practices and emerging policy pathways for urban agriculture. Land Use Policy, 68 (November 2017): 334-344.

Wilkinson, S. (2011) Analysing focus group data. In D. Silverman (Ed.) Qualitative research ( $3^{\text {rd }}$ ed.) London: Sage, 168-186.

Wolch, J. R., Byrne, J., and Newell, J. P. (2014). Urban green space, public health, and environmental justice: The challenge of making cities 'just green enough'. 
Pre-Print Version, accepted for publication in Landscape and Urban Planning on $7^{\text {th }}$ September 2019

Landscape and Urban Planning, 125: 234-244.

doi:http://dx.doi.org/10.1016/j.landurbplan.2014.01.017 